\title{
A Rare Variation of Suprascapular Artery Originated from the Axillary Artery
}

\author{
Una Rara Variación de la Arteria Supraescapular Originada de la Arteria Axilar
}

\author{
Quan Zhang ${ }^{1}$; Ruhong Zhuo ${ }^{2}$; Liu $\mathrm{He}^{1}$ \& Chengjun $\mathrm{Hu}^{1}$
}

ZHANG, Q.; ZHUO, R.; HE, L.\& HU, C. A rare variation of suprascapular artery originated from the axillary artery. Int. J. Morphol., 37(3):1046-1048, 2019.

SUMMARY: The suprascapular artery (SSA) has been identified to be of clinical relevance to clavicular fracture, suprascapular neuropathy and surgical intervention of shoulder. Thus its origin and course have been intensively studied. In this case, we found a unilateral variation of the suprascapular artery, originating from the 1st segment of axillary artery, and sequentially penetrating the upper trunk of brachial plexus, passing through the suprascapular notch under the superior transverse scapular ligament. This case will be helpful to clinical management in cervical and shoulder region.

KEY WORDS: Suprascapular artery; Variation; Axillary artery.

\section{INTRODUCTION}

Because of the clinical relevance to clavicular fracture, suprascapular neuropathy and surgical intervention of shoulder, the origin and course of suprascapular artery has been intensively studied.

Usually, the suprascapular artery originates from the thyrocervical trunk, then it runs laterally to posterior cervical triangle. During the course, it passes in front of the scalene anterior muscle, the phrenic nerve, the third part of the subclavian artery and the primary cords of the brachial plexus sequentially. Afterwards, it reaches the superior margin of the scapula, and finally it passes over the superior transverse scapular ligament (STSL) to enter the supraspinous fossa.

In the present report, we found a unilateral variation of suprascapular artery. This variation is rare, and will be helpful to clinical practice.

\section{CASE REPORT}

During a routine educational dissection of a male cadaver in his sixties in Human Body Course, who has been perfused by latex through right common carotid artery, a unilateral variation in origin and course of SSA was observed on the left side. In order to have a clear view of SSA in the root of neck, clavicles from both ends have been cut off. This anomalous SSA originated from the 1st segment of axillary artery, $6.0 \mathrm{~cm}$ distal to the origin of thyrocervical trunk and $2.1 \mathrm{~cm}$ proximal to the thoraco-acromial artery. Its origin was $0.4 \mathrm{~cm}$ in diameter. This SSA passed in front of the lower and middle trunks of brachial plexus, then it penetrated upper trunk through the gap between its anterior and posterior divisions. Afterwards, the SSA meet the SSN, and when they reached the suprascapular notch they passed inferior to the STSL in parallel and entered into the suprascapular fossa (Fig. 1). On the right side, SSA originated from the thyrocervical trunk and then went laterally in front of the scalene anterior muscle, brachial plexus, finally it crossed over the STSL, while the SSN passed inferior to it.

\section{DISCUSSION}

The origin and course of SSA have been extensively studied. In this case, we found an unusual origin from the

\footnotetext{
${ }^{1}$ Department of Anatomy and Embryology, Wuhan University School of Medicine, Wuhan University, Wuhan, Hubei 430071, P.R. China.

${ }^{2}$ Department of Integrated Medicine, Zhongnan Hospital of Wuhan University, 430071, P.R. China.

Supported by grants from Hubei Provincial Natural Science Foundation of China (2018CFB781) and the Education \& Teaching Reform Funds for the Central Universities in Wuhan University (2017JG052).
} 


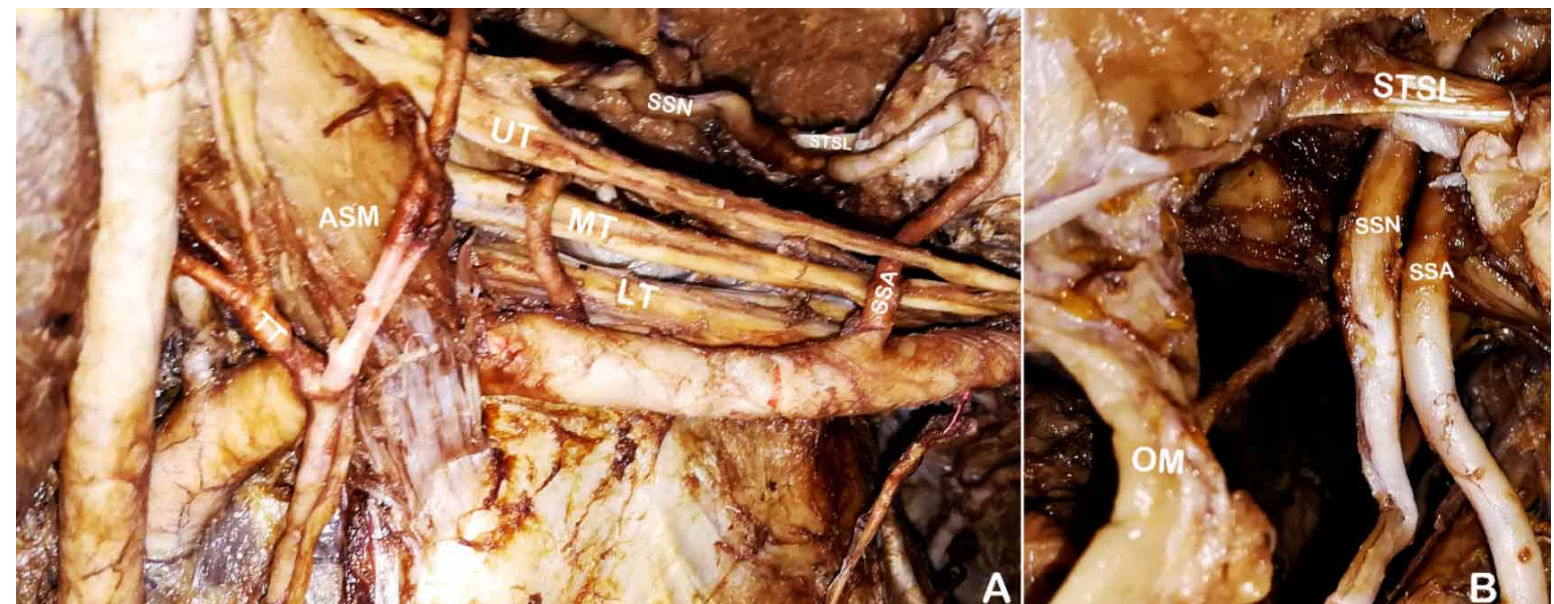

Fig. 1. A. the root of neck on the left side (anterior view). B. left SSA and SSN pass inferior to the STSL (superior view). SSA: suprascapular artery. SSN: suprascapular nerve. STSL: superior transverse scapular ligament. OM: omohyoid muscle. UT: upper trunk of brachial plexus. MT: middle trunk of brachial plexus. LT: lower trunk of brachial plexus. TT: thyrocervical trunk. ASM: Anterior scalene muscle.

1 st segment of axillary artery. This variation is also reported by Naidoo et al. (2014) and Singh (2018) with the rate as 2 $\%(2 / 100)$ and $3.6 \%(1 / 28)$ respectively. Besides, Pyrgakis et al. (2013) reported $1.6 \%(1 / 62)$ origin from the 3 rd part of subclavian artery but no origin from the axillary artery. The SSA supplies the tendinous rotator cuff of the shoulder joint. Therefore, surgeons should keep its anomalous origin in mind when managing some diseases in the cervical and shoulder regions. Also, the anomalous origin of SSA from the 1 st segment of the axillary artery makes it originate almost behind the external third of the clavicle instead of the middle $1 / 3$ segment of clavicle, the latter is the usual region of clavicular fracture, so the probability of its damage by fractured clavicle is lower.

The relationship between SSA and STSL also has been reported by many authors (Chen \& Adds, 2011; Polguj et al., 2015). Typical SSA passes superior to the STSL, while SSN passes inferior to it. But in this case we found on the left side SSA and SSN passed together through the suprascapular notch below the STSL. This subligamentous SSA has also been reported by others with the rate ranging from $1.6 \%$ to $20 \%$ (Tubbs et al., 2003; Yang et al., 2012; Pyrgakis et al.; Naidoo et al.). When SSA accompanies SSN, it reduces the capacity of suprascapular notch and chronically induces friction, inflammation and finally constriction of the SSN, leading to suprascapular neuropathy and dysfunction.

As we know, reports about relationship between brachial plexus and SSA are very limited. In most cases, the SSA passed in front of the brachial plexus, while in this case we found SSA passed between the anterior and posterior divisions of upper trunk of brachial plexus. Similarly,
Dargaud et al. (2002) found that $29 \%$ SSA passed behind the brachial plexus or passed between the trunks of the brachial plexus. To know this variation will help surgeons to avoid iatrogenic injury to SSA in extra-articular endoscopic surgeries (Lafosse et al., 2015).

\section{ACKNOWLEDGMENTS}

This work was supported by grants from Hubei Provincial Natural Science Foundation of China (2018CFB781) and the Education \& Teaching Reform Funds for the Central Universities in Wuhan University (2017JG052).

ZHANG, Q.; ZHUO, R.; HE, L.; HU, C. variación de la arteria supraescapular originada de la arteria axilar. Int. J. Morphol., 37 (3):1046-1048, 2019,

RESUMEN: Se ha identificado que la arteria supraescapular (ASS) tiene relevancia clínica en la fractura clavicular, la neuropatía supraescapular y la intervención quirúrgica del hombro. En consecuencia, su origen y su curso han sido ampliamente estudiados. En este caso, encontramos una variación unilateral de la arteria supraescapular, originada en el primer segmento de la arteria axilar, y que penetraba secuencialmente en el tronco superior del plexo braquial, pasando a través de la incisura supraescapular debajo del ligamento escapular transverso superior. Este caso será útil para el manejo clínico en la región cervical y del hombro.

PALABRAS CLAVE: Arteria supraescapular; Variación; Arteria axilar. 


\section{REFERENCES:}

Chen, D. \& Adds, P. Accessory suprascapular artery. Clin. Anat., 24(4):498500,2011

Dargaud, J.; Galichon, V.; Dargaud, Y.; Quesnel, T. \& Morin, A. Study of the relationship between the suprascapular artery and the brachial plexus. Surg. Radiol. Anat., 24(2):108-12, 2002.

Lafosse, T.; Masmejean, E.; Bihel, T. \& Lafosse, L. Brachial plexus endoscopic dissection and correlation with open dissection. Chir. Main, 34(6):286-93, 2015.

Naidoo, N.; Lazarus, L.; De Gama, B. Z. \& Satyapal, K. S. The variant course of the suprascapular artery. Folia Morphol.(Warsz), 73(2):2069, 2014.

Polguj, M.; Rozniecki, J.; Sibinski, M.; Grzegorzewski, A.; Majos, A. \& Topol, M. The variable morphology of suprascapular nerve and vessels at suprascapular notch: a proposal for classification and its potential clinical implications.Knee Surg. Sports Traumatol. Arthrosc., 23(5):1542-8, 2015.

Pyrgakis, P.; Panagouli, E. \& Venieratos, D. Anomalous origin and course of the suprascapular artery combined with absence of the suprascapular vein: case study and clinical implications. N.Am.J.Med.Sci., 5(2):12933, 2013.

Singh, R. Variations in the origin and course of the suprascapular artery: case report and literature review. J. Vasc. Bras., 17(1):61-5, 2018.

Tubbs, R. S.; Smyth, M. D.; Salter, G. \& Oakes, W. J. Anomalous traversement of the suprascapular artery through the suprascapular notch: a possible mechanism for undiagnosed shoulder pain? Med.Sci. Monit., 9(3):BR116-9, 2003.

Yang, H. J.; Gil, Y. C.; Jin, J. D.; Ahn, S. V. \& Lee, H. Y. Topographical anatomy of the suprascapular nerve and vessels at the suprascapular notch. Clin. Anat., 25(3):359-65, 2012.
Corresponding author:
Dr. Chengjun $\mathrm{Hu}$

Department of Anatomy and Embryology

Wuhan University School of Medicine

185 Donghu Road

Wuhan, Hubei 430071

P.R. CHINA

Email: chengjunhu@whu.edu.cn

Received: 25-10-2018

Accepted: 04-02-2019 